\title{
MATERNAL AND FOETAL OUTCOME IN PREGNANCIES COMPLICATED WITH HYPOTHYROIDISM IN PUNJABI WOMEN
} \author{
Ashish Ahuja ${ }^{8}$ \\ ${ }^{1}$ Associate Professor, Department of Endocrinology, DMC \& H, Ludhiana. \\ 2 Professor, Department of Obstetrics and Gynaecology, DMC \& H, Ludhiana. \\ ${ }^{3}$ Assistant Professor, Department of Obstetrics and Gynaecology, DMC \& H, Ludhiana. \\ ${ }^{4}$ Senior Resident, Department of Obstetrics and Gynaecology, DMC \& H, Ludhiana. \\ ${ }^{5}$ Senior Resident, Department of Obstetrics and Gynaecology, DMC \& H, Ludhiana. \\ ${ }_{6}^{6}$ Associate Professor, Department of Obstetrics and Gynaecology, DMC \& H, Ludhiana. \\ ${ }^{7}$ Assistant Professor, Department of Paediatrics, DMC \& H, Ludhiana. \\ ${ }^{8}$ Associate Professor, Department of Surgery, DMC \& H, Ludhiana.
}

Manikant Singla1, Sunil Kumar Juneja², Pooja Tandon³, Preet Kanwal Kaur, Bakul Kochhar, Shweta Gupta6, Kamaldeep Arora7

\begin{abstract}
Pregnancy is a state that places great physiological stress on both the mother and the foetus. When pregnancy is compounded by endocrine disorders such as hypothyroidism, the potential for maternal and foetal adverse outcomes can be immense.

\section{OBJECTIVE}

We performed a study to know the incidence of hypothyroidism in Punjab and to know the various maternal and foetal complications associated with it.
\end{abstract}

\section{MATERIAL AND METHODS}

A retrospective study was performed on pregnant patients delivered between 2010-2014 in Dayanand Medical College and Hospital, Ludhiana. The patients were evaluated for antenatal, intrapartum and postpartum maternal and foetal complications, period of gestation at delivery, mode of delivery and neonatal outcome.

\section{RESULTS}

Out of total 5400 pregnant women who delivered at DMCH, Ludhiana, 189 (3.5\%) women were hypothyroid. History of spontaneous abortions was present in 54 (28.57\%) women and gestational hypertension was present in 22 (11.64\%) women. Preterm rupture of membrane was present in 18 (9.52\%) women. GDM was present in $9(4.76 \%)$ women and oligohydramnios was present in 14 (7.40\%) women. Caesarean section was done in 37 (46.56\%) women, out of which 37 (19.58\%) had foetal distress. There were $94(49.74 \%)$ women who delivered between 33-37 wks. gestation. PPH was present in $8(4.23 \%)$ women. There were $87(46.03 \%)$ babies who were having low birth weight and there were $6(3.17 \%)$ neonatal deaths. There were $8(4.23 \%)$ still births.

\section{CONCLUSION}

As hypothyroidism is associated with various maternal and foetal complications, proper diagnosis and treatment should be done.

\section{KEYWORDS}

Gestational, Diabetes Mellitus, Maternal, Foetal, Glucose, Outcomes.

HOW TO CITE THIS ARTICLE: Singla M, Juneja SK, Tandon P, et al. Maternal and foetal outcome in pregnancies complicated with hypothyroidism in Punjabi women. J. Evolution Med. Dent. Sci. 2016;5(56):3826-3829, DOI: 10.14260/jemds/2016/876

\section{INTRODUCTION}

Pregnancy is a state that has a great impact on the thyroid gland and its functions. In pregnancy, the levels of T3 and T4 increase due to the increased Thyroid Binding Globulin levels (TBG). Due to the thyrotrophic action of hCG, the levels of TSH decrease in pregnancy. ${ }^{1,2}$ In pregnant patients with limited thyroidal reserve, hypothyroidism develops. So the range of TSH throughout the pregnancy is lowered. In first trimester, upper reference limit is $2.5 \mathrm{uIU} / \mathrm{mL}$ and for second and third trimester this limit is $3 \mathrm{uIU} / \mathrm{mL}^{3}$

Financial or Other, Competing Interest: None.

Submission 13-05-2016, Peer Review 10-06-2016,

Acceptance 16-06-2016, Published 12-07-2016.

Corresponding Author:

Dr. Ashish Ahuja,

\#132/1,

Rani Jhansi Road,

Ludhiana.

E-mail: drahuja17@gmail.com

DOI: $10.14260 /$ jemds $/ 2016 / 876$
Incidence of overt hypothyroidism is approximately $0.5 \% .4,5$ which is defined by fall in free T4 levels and rise of TSH levels. $6,7,8$ Overt hypothyroidism is associated with adverse pregnancy outcomes as well as poor foetal neurocognitive development. ${ }^{9}$ Overt hypothyroidism is associated with increased risk of abortion, anaemia, gestational hypertension, gestational diabetes, placental abruption and postpartum haemorrhage. ${ }^{10,11}$ There is increased incidence of premature birth, low birth weight and neonatal respiratory distress. ${ }^{12,13}$ It has also been associated with increased risk of foetal loss and perinatal mortality. ${ }^{14}$ It may also increase the rate of caesarean section. ${ }^{15}$ Prevalence of subclinical hypothyroidism is approximately $1.5 \% .{ }^{15}$ Various studies have mixed data on the effect of subclinical hypothyroidism on adverse pregnancy outcome. ${ }^{10,16}$

ACOG does not recommend universal thyroid screening. To assess the thyroid status in pregnancy, TSH is the first line screening test. Free T4 is added to confirm the diagnosis. 
Treatment of overt hypothyroidism is recommended to minimize the risk of adverse pregnancy effects. Monitoring with TSH should be done and dose of thyroid replacement therapy should be adjusted accordingly. ${ }^{17}$

\section{AIM OF THE STUDY}

The aim of the study was to evaluate the maternal and foetal outcome in pregnant patients with hypothyroidism in Punjabi population. The study also aims to know the incidence of hypothyroidism in pregnancy in Punjabi population.

\section{MATERIAL AND METHODS}

A retrospective study was done on pregnant patients who were admitted in the Department of Obstetrics and Gynaecology, Dayanand Medical College and Hospital, Ludhiana, from January 2010 to December 2014. Out of the total patients delivered, the patients with overt and subclinical hypothyroidism were taken into the study. Presence of any maternal and/or foetal complication was noted. The data was statistically analysed.

\section{RESULTS}

The total number of patients who delivered in Department of Obstetrics and Gynaecology from January 2010 to December 2014 were 5400 . A retrospective analysis of the patients with various associated complications was done.

\begin{tabular}{|c|c|}
\hline Total Number of Deliveries & 5400 \\
\hline $\begin{array}{c}\text { Patients with } \\
\text { Hypothyroidism }\end{array}$ & $189(3.5 \%)$ \\
\hline
\end{tabular}

Out of the total 5400 women, $189(3.5 \%)$ women were found to be hypothyroid. Hence, the incidence of the hypothyroidism in pregnant patients in Punjabi population comes out to be $3.5 \%$,

\begin{tabular}{|c|c|}
\hline Mean Age of Patients & $26+/-5$ years \\
\hline $\begin{array}{c}\text { History of Previous } \\
\text { Miscarriage }\end{array}$ & $54(28.57 \%)$ \\
\hline
\end{tabular}

The mean age of women was $26+/-5$ years. Out of total 189 women, 54 (28.57\%) had history of previous miscarriage.

Associated Maternal Complications
\begin{tabular}{|c|c|}
\hline Gestational hypertension & $22(11.64 \%)$ \\
\hline $\begin{array}{c}\text { Gestational diabetes } \\
\text { mellitus }\end{array}$ & $9(4.76 \%)$ \\
\hline Oligohydramnios & $14(7.40 \%)$ \\
\hline PROM & $18(9.52 \%)$ \\
\hline Foetal distress & $37(19.58 \%)$ \\
\hline Caesarean section & $88(46.56 \%)$ \\
\hline
\end{tabular}

There were 22 (11.64\%) patients who had gestational hypertension. Gestational diabetes mellitus was present in 9 (4.76\%) women. Oligohydramnios was present in $14(7.40 \%)$ women. There were 18 (9.52\%) women, who had PROM. Caesarean section was done in $88(46.56 \%)$ women, out of which 37 (19.58\%) women had foetal distress.

\section{PREGNANCY OUTCOME}

\begin{tabular}{|c|c|}
\hline Preterm delivery & $94(49.7 \%)$ \\
\hline Term delivery & $95(50.3 \%)$ \\
\hline
\end{tabular}

There were 94 (49.74\%) women who delivered preterm between 33-37 wks. of gestation. There were 95 (50.3\%) women who had term delivery. Postpartum haemorrhage occurred in 18 (19.52\%) women.

\section{FOETAL OUTCOME}

\begin{tabular}{|c|c|}
\hline Still born & $8(4.23 \%)$ \\
\hline Live born & $181(95.7 \%)$ \\
\hline Neonatal deaths & $6(3.17 \%)$ \\
\hline Perinatal mortality rate & $7.4 \%$ \\
\hline Birth weight $<2.5 \mathrm{~kg}$ & $87(46.03 \%)$ \\
\hline
\end{tabular}

Out of total babies born, 8 (4.23\%) babies were stillborn. There were 181 (95.7\%) of babies who were live born; however, there were $6(3.17 \%)$ babies who died during the neonatal period. Perinatal mortality was $7.4 \%$. There were 87 $(46.03 \%)$ babies who had low birth weight $(<2.5 \mathrm{~kg})$.

\section{DISCUSSION}

In pregnancy, the size of thyroid gland increases to meet the increased metabolic demands of the body. 18 Patients with limited reserve of thyroid hormone or iodine deficiency develop hypothyroidism in pregnancy. Autoimmune thyroid disease (Hashimoto's disease) and iodine deficiency, especially in endemic areas are the common causes of hypothyroidism in pregnancy. ${ }^{3}$ It has been well studied and documented that hypothyroidism in pregnant patients is associated with adverse maternal and foetal outcomes. ${ }^{19}$ The incidence of hypothyroidism in our study is 3.5\%. The incidence in various other studies has been studied and found to be $4.8 \% .^{18} 2.5 \% .^{20} 2.6 \%{ }^{21}$ and $3.69 \% .{ }^{22}$

The mean age of women in our study was $26+/-5$ years. In various other studies, the mean age was $25.19 \pm 4.17$ years. ${ }^{18}$, $27+/-6$ years. ${ }^{21}$ and $29 \pm 5$ years. ${ }^{10}$ Early marriage in our country may be one reason for the younger age of presentation in our study. There were $28.5 \%$ women who had history of miscarriage. In a study done by Abalovich et al, this rate was $31.4 \% .^{10}$ In another study by Nambiar et al, this rate was 26.3\%.18 Autoimmune thyroid disease and subclinical hypothyroidism has been associated with increased rates of abortion. Various maternal complications in our study were documented. Gestational hypertension was present in $11.64 \%$ in our study. In a study done by Davis et al, $44 \%$ untreated hypothyroid women had gestational hypertension. ${ }^{23}$ Rate of gestational hypertension in other studies were $26.9 \% .24$, $15.6 \% .{ }^{25}$ and $44.6 \% .{ }^{26}$

In hypothyroidism, there occurs impaired endothelium derived vasodilatation due to decreased nitric oxide secretion, which causes increased risk of hypertension in these patients. ${ }^{27}$ The rate of gestational diabetes mellitus, PROM in our study is $4.76 \%, 9.52 \%$ respectively. Incidence of gestational DM in a study done by Tudela et al was $4.9 \% .{ }^{28}$ Risk of GDM increases four-fold in women with hypothyroidism. ${ }^{29}$ Insulin and thyroid hormones both affect the cell metabolism and any alteration in either of them affects the physiology of other hormone. 30 The incidence of oligohydramnios in our study is $7.4 \%$. In another study done by Sejekan, this rate was $3.9 \% .{ }^{25}$ In our study, $49.7 \%$ of babies had preterm birth. This incidence was $60 \%$ in a study done by Rodica et al. 31 The incidence of low birth weight babies in our study was $46.03 \%$. Low birth weight of babies is due to preterm birth of these 
babies. The risk of low birth weight increases to three fold in patients with hypothyroidism. In other studies, this incidence was $31 \% .^{23}, 15.4 \% .^{24}$ and $19.8 \% .^{14}$ The presence of autoimmune thyroid antibodies is also associated with high risk of preterm birth and hence low birth weight of babies. Coexistence of pre-eclampsia and oligohydramnios also increases the incidence of preterm birth and PROM. In our study, $19.52 \%$ of patients had PPH. In similar other studies, this incidence was $19 \%{ }^{23}, 7 \% .^{24}$ and $16 \%{ }^{31} \mathrm{PPH}$ in patients with hypothyroidism is secondary to uterine hypotonia and coagulation disorders. ${ }^{27}$

In our study $46.56 \%$ of women underwent caesarean section, out of which $19.58 \%$ had foetal distress. The incidence of caesarean section rate was $40 \% .^{31}$ and $28.7 \% .^{14}$ in other studies. In hypothyroidism there occurs labour abnormalities due to the associated uterine hypotonia, which increases the chances of caesarean delivery. ${ }^{31}$ Apart from this, chances of caesarean section also increase due to foetal distress which may be secondary to various other associated complications. In our study, $4.83 \%$ of pregnancies ended in stillbirth. In a study by Leung et al, $1.4 \%$ of women had still birth. ${ }^{26}$ The overall perinatal mortality in our study was $7.4 \%$. This rate was $3.9 \%$ and $1.9 \%$ in studies done by Buckshee et al and Sejekan respectively.24,25 Various complications in hypothyroidism has been associated with perinatal mortality.

\section{CONCLUSION}

Hypothyroidism in pregnancy is not an uncommon finding. It has been associated with poor maternal and neonatal outcome. Various studies have been done in developed countries to study the incidence and outcome of hypothyroidism in pregnant women. But there are few studies in developing country like India. We, therefore, performed a study to know the incidence of hypothyroidism in pregnant women in Punjab and its consequences on maternal and foetal outcome. It has been seen that hypothyroidism adversely affects maternal and foetal outcome. So, diagnosing the patients with hypothyroidism and starting early treatment and close antenatal and postpartum follow-up of these patients help in preventing and diagnosing the complications associated with hypothyroidism, thus reducing the maternal and foetal morbidities.

\section{REFERENCES}

1. Glinoer D. The regulation of thyroid function in pregnancy: pathways of endocrine adaptation from physiology to pathology. Endocr Rev 1997;18(3):404-33.

2. Baloch Z, Carayon P, Conte-Devolx B, et al. Laboratory medicine practice guidelines. Laboratory support for the diagnosis and monitoring of thyroid disease. Thyroid 2003;13(1):3-126.

3. Stagnaro-Green A, Abalovich M, Alexander E, et al Guidelines of the American thyroid association for the diagnosis and management of thyroid disease during pregnancy and postpartum. Thyroid 2011;21(10): 1081-125.

4. Allan WC, Haddow JE, Palomaki GE, et al. Maternal thyroid deficiency and pregnancy complications: implications for population screening. J Med Screen 2000;7(3):127-30.

5. Klein RZ, Haddow JE, Faix JD, et al. Prevalence of thyroid deficiency in pregnant women. Clinical Endocrinology 1991;35(1):41-6.
6. Casey BM, Dashe JS, Wells CE, et al. Subclinical hypothyroidism and pregnancy outcomes. Obstetrics and Gynaecology 2005;105(2):239-45.

7. Stagnaro-Green A, Roman $\mathrm{SH}$, Cobin $\mathrm{RH}$, et al. A prospective study of lymphocyte-initiated immunosuppression in normal pregnancy: evidence of a T-cell aetiology for postpartum thyroid dysfunction. Journal of Clinical Endocrinology and Metabolism 1992;74(3):645-53.

8. Stagnaro-Green A. Overt hyperthyroidism and hypothyroidism during pregnancy. Clinical Obstetrics and Gynaecology 2011;54(3):478-87.

9. Haddow JE, Palomaki GE, Allan WC, et al. Maternal thyroid deficiency during pregnancy and subsequent neuropsychological development of the child. N Engl J Med 1999;341(8):549-55.

10. Abalovich M, Gutierrez S, Alcaraz G, et al. Overt and subclinical hypothyroidism complicating pregnancy Thyroid 2002;12(1):63-8.

11. Papazafiropoulou A, Sotiropoulos A, Kokolaki A, et al. Prevalence of thyroid dysfunction among Greek type 2 diabetic patients attending an outpatient clinic. J Clin Med Res 2010;2(2):75-8.

12. LaFranchi SH, Haddow JE, Hollowell JG. Is thyroid inadequacy during gestation a risk factor for adverse pregnancy and developmental outcomes? Thyroid 2005;15(1):60-71.

13. Martin MN. Management of hypothyroidism during pregnancy. Clinical Obstetrics Gynaecology 1997;40(1):65-80.

14. Idris I, Srinivasan R, Simm A, et al. Maternal hypothyroidism in early and late gestation: effects on neonatal and obstetric outcome. Clinical Endocrinology 2005;63(5):560-5.

15. Casey BM, Leveno KJ. Thyroid disease in pregnancy. Obstet Gynaecol 2006;108(5):1283-92.

16. Cleary-Goldman J, Malone FD, Lambert-Messerlian G, et al. Maternal thyroid hypofunction and pregnancy outcome. Obstetrics and Gynaecology 2008;112(1):85-92.

17. Kilpatrick SJ. ACOG Practice Bulletin Number 148: thyroid disease in pregnancy. Obstet Gynaecol 2015;125(4):9961005.

18. Nambiar V, Jagtap VS, SarathI V, et al. Prevalence and impact of thyroid disorders on maternal outcome in Asian-Indian pregnant women. Journal of Thyroid Research Article ID 429097, 2011:6 pgs.

19. Chang DLF, Pearce EN. Screening for maternal thyroid dysfunction in pregnancy: a review of the clinical evidence and current guidelines. Journal of Thyroid Research Article ID 851326, 2013:8 pgs.

20. Glinoer D, Riahi M, Grun JP, et al. Risk of subclinical hypothyroidism in pregnant women with asymptomatic autoimmune thyroid disorders. The Journal of Clinical Endocrinology and Metabolism 1994;79(1):197-204.

21. Vaidya B, Anthony S, Bilous M, et al. Detection of thyroid dysfunction in early pregnancy: universal screening or targeted high-risk case finding? The Journal of Clinical Endocrinology and Metabolism 2007;92(1):203-7.

22. Mukhopadhyay A, Pati S, Mukherjee S, et al. Autoimmune thyroid disorders and pregnancy outcome: a prospective observational study. Thyroid Research and Practice 2007;4(1):50-2. 
23. Davis LE, Leveno KJ, Cunningham FG. Hypothyroidism complicating pregnancy. Obstet Gynaecol 1988;72(1): 108-12.

24. Buckshee K, Kriplani A, Kapil A, et al. Hypothyroidism Complicating pregnancy. Australian and New Zealand Journal of Obstetrics and Gynaecology 1992;32(3):240-2.

25. Prema S. Thyroid screening in pregnancy - a study of 82 women. J Obstet Gynaecol India 2010;60(3):232-6.

26. Leung AS, Millar LK, Koonings PP, et al. Perinatal outcome in hypothyroid pregnancies. Obstet Gynaecol 1993; 81(3) :349-53.

27. Taddei S, Caraccio N, Virdis A, et al. Impaired endothelium-dependent vasodilatation in subclinical hypothyroidism: beneficial effect of levothyroxine therapy. J Clin Endocrinol Metab 2003; 88 (8):3731-7.
28. Tudela CM, Casey BM, McIntire DD, et al. Relationship of subclinical thyroid disease to the incidence of gestational diabetes. Obstet Gynaecol 2012;119(5):983-8.

29. Hajieh S, Behbahani M, Mohtashami AZ. Prevalence of thyroid dysfunction and thyroid auto-antibodies in type 2 diabetic patients. Pak J Med Sci 2011;27(5):1169-72.

30. Karakosta P, Alegakis D, Georgiou V, et al. Thyroid dysfunction and autoantibodies in early pregnancy are associated with increased risk of gestational diabetes and adverse birth outcomes. J Clin Endocrinal Metab 2012;97(12):4464-72.

31. Tudosa R, Vartej P, Horhoianu I, et al. Maternal and foetal complications of the hypothyroidism-related pregnancy. Maedica Journal of Clinical Medicine 2010; 5(2):116-23. 